\title{
Application of Quantum Cascade Lasers in Nitric Oxide and Nitrous Oxide Detection
}

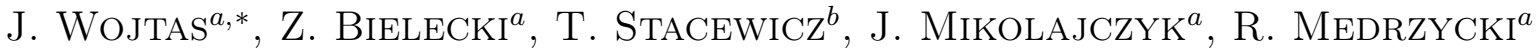 \\ AND B. RUTECKA ${ }^{a}$ \\ ${ }^{a}$ Institute of Optoelectronics, Military University of Technology, S. Kaliskiego 2, 00-908 Warsaw, Poland \\ ${ }^{b}$ Institute of Experimental Physics, Dept. of Physics, University of Warsaw, Hoża 69, 00-681 Warsaw, Poland \\ Application of quantum cascade lasers in $\mathrm{NO}$ and $\mathrm{N}_{2} \mathrm{O}$ sensor is described. Cavity enhanced absorption \\ spectroscopy was used for this purpose. The detection was performed at vibronic molecular transitions in spectral \\ regions of 5.23-5.29 $\mu \mathrm{m}$ and 4.46-4.54 $\mu \mathrm{m}$ for $\mathrm{NO}$ and $\mathrm{N}_{2} \mathrm{O}$, respectively. In order to avoid interferences by the \\ gases contained in atmosphere $\left(\mathrm{H}_{2} \mathrm{O}, \mathrm{CO}_{2}\right)$ the lines of $5.263 \mu \mathrm{m}$ for $\mathrm{NO}$ and $4.530 \mu \mathrm{m}$ for $\mathrm{N}_{2} \mathrm{O}$ were selected. \\ Our two channel sensor is designated for simultaneous detection of both compounds. Each channel consists of \\ single mode quantum cascade laser, optical cavity, and a photodetection module. The lasers were precisely tuned \\ to the wavelength of interest. Optical cavities were built with spherical mirrors of high reflectance. The signals \\ from the cavities outputs were registered with specially developed low noise detection modules.
}

PACS: 07.07.Df, 42.25.Dd, 42.55.Px, 42.60.Da, 42.62.Fi

\section{Introduction}

Nitrogen oxides are important compounds of air. According to Hitran database, in standard atmosphere their concentrations are as follows: $\mathrm{NO}-0.3 \mathrm{ppbv}, \mathrm{NO}_{2}-$ 23 pptv, $\mathrm{N}_{2} \mathrm{O}-320$ ppbv [1]. However, in real ambient air these values differ strongly due to influence of various emission sources (anthropogenic and natural). Atmospheric chemistry and photochemistry lead to a complicated mechanism of $\mathrm{NO}_{x}$ production involving air compounds and pollutants. It also leads to conversions among nitrogen oxides [2]. $\mathrm{NO}_{x}$ have a large influence on environment, living organisms and human health. They are important greenhouse gases. Acid rains occur due to reactions of these compounds with $\mathrm{H}_{2} \mathrm{O}$ contained in air. Moreover, $\mathrm{NO}, \mathrm{NO}_{2}$ and $\mathrm{N}_{2} \mathrm{O}$ are produced due to decomposition of specific explosive materials so these gases can be used as markers [3-5]. Therefore the monitoring of $\mathrm{NO}_{x}$ is of great importance for various applications: from routine air research in industrial area and regions of intensive traffic, to detection of explosives in airports, finally for medicine investigation, for health care, etc. $[6,7]$.

These applications provide a significant impact on the performance of novel sensors. By now nitrogen oxides are detected mainly with chemical methods [8, 9]. Fast progress in semiconductor lasers and photodetectors technology provides opportunity to construct a fully optoelectronic $\mathrm{NO}_{x}$ sensors, based on measurement of light

* corresponding author; e-mail: jwojtas@wat.edu.pl absorption at wavelengths which are characteristic for molecules of interest. Such constructions might be more sensitive, compact and cheap than the chemical ones.

\section{Experimental setup}

Figure 1 presents the absorption spectra of the most common nitrogen oxides in UV-VIS-IR range. $\mathrm{NO}_{2}$ can be well detected with blue violet lasers $(0.4-0.42 \mu \mathrm{m})$. Such approach was already demonstrated by several laboratories [10-15]. Mean value of the absorption cross-section in this region reaches about $6 \times 10^{-19} \mathrm{~cm}^{2}$. Therefore in order to achieve the sensitivity of $1 \mathrm{ppb}$ (which is competitive to chemical methods) one must ensure the detection limit of the absorption coefficient of about $1.5 \times 10^{-8} \mathrm{~cm}^{-1}$. The cross-sections for $\mathrm{NO}$ and $\mathrm{N}_{2} \mathrm{O}$ are similar or higher to these of $\mathrm{NO}_{2}$ than the comparable sensitivity might be expected. However measurement of such low absorption requires special methods like cavity ring down spectroscopy (CRDS) [16, 17]. This technique is based on investigation of quality factor of an optical resonator composed of two mirrors characterized by very high reflectivity coefficient $R$. When the cavity is filled with an absorber the value of $Q$-factor decreases in comparison with empty resonator. Therefore measuring the resonator quality, the determination of absorption coefficient is possible. Extreme detection limit which is available with this method exceeds even $10^{-10} \mathrm{~cm}^{-1}$.

UV-blue absorption band of $\mathrm{NO}_{2}$ corresponds to electronic transition in the molecule. Second absorption band of $\mathrm{NO}_{2}$ molecule (vibronic transitions) which is 


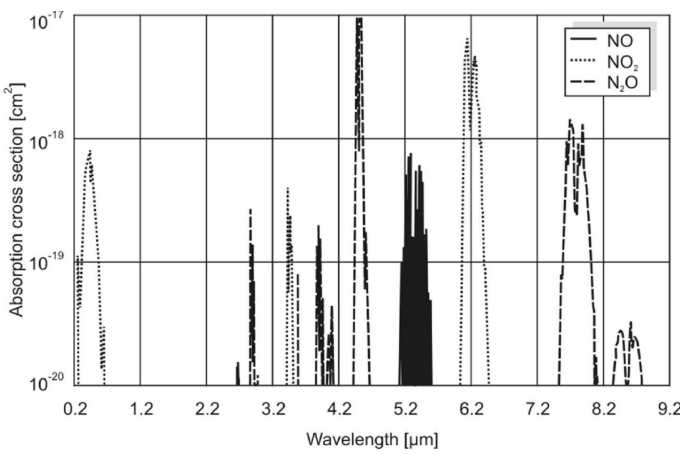

Fig. 1. Absorption spectra of $\mathrm{NO}_{2}, \mathrm{~N}_{2} \mathrm{O}$ and $\mathrm{NO}$ in UV-VIS-IR range.

located around $6.2 \mu \mathrm{m}$ is characterized by larger cross-section than the blue one. However, due to lack of compact semiconductor lasers, it is not so useful at present.

Absorption bands of electronic transitions of $\mathrm{NO}$ and $\mathrm{N}_{2} \mathrm{O}$ molecules are located in UV range at wavelengths inaccessible for CRDS technique due to lack of highly reflective mirrors for this spectral region. However the bands corresponding to vibronic transitions around $5.26 \mu \mathrm{m}$ for $\mathrm{NO}$ and $4.53 \mu \mathrm{m}$ for $\mathrm{N}_{2} \mathrm{O}$ might be treated with contemporary quantum cascade lasers (QCL). In this paper we describe an experiment where such opportunity of detection of nitric oxide and nitrous oxide was investigated.

Quantum cascade lasers were already applied for NO detection with multipass cell and with CRDS technique [18] at the air pressure reduced to 30 Torr, as well as with photoacoustic spectroscopy [19]. Here we present the construction of the system which is able to detect simultaneously $\mathrm{NO}$ and $\mathrm{N}_{2} \mathrm{O}$ at atmospheric pressure.

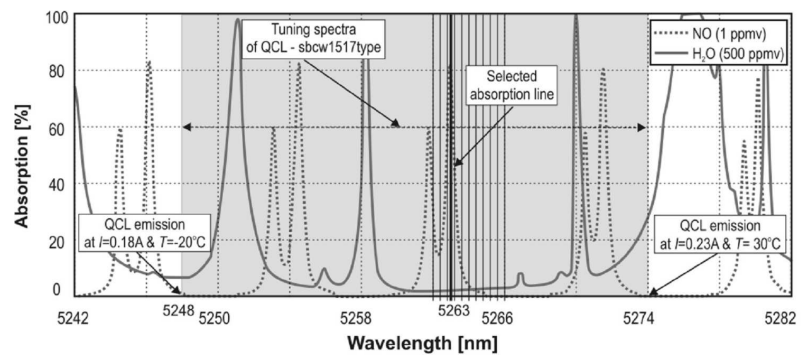

Fig. 2. Normalized absorption spectra of NO (dotted line) and $\mathrm{H}_{2} \mathrm{O}$ (continuous line).

Avoiding of interferences is one of the most important problems in the detection based on measurement of light absorption. They can occur due to influence of other gases whose absorption spectra overlap with the spectrum of investigated compound. $\mathrm{H}_{2} \mathrm{O}$ which is commonly present in the atmosphere is the most interfering compound in spectral ranges mentioned above. Figure 2 and 3 present a comparison of normalized absorption spectra of nitrogen oxide and nitrous oxide with water

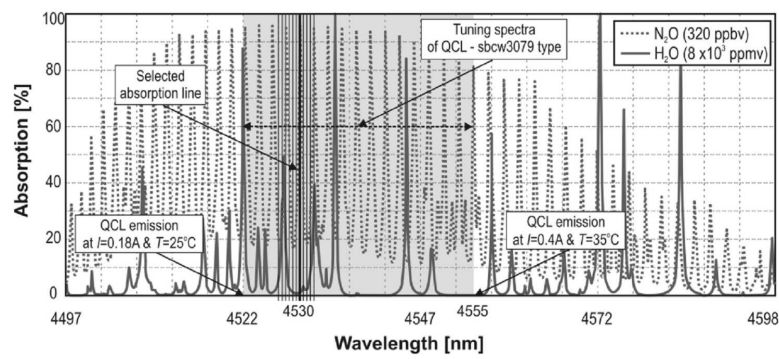

Fig. 3. Normalized absorption spectra of $\mathrm{N}_{2} \mathrm{O}$ (dotted line) and $\mathrm{H}_{2} \mathrm{O}$ (continuous line).

vapour for standard atmosphere [20], respectively. Note that the spectra consist of narrow separated lines corresponding to transition between ro-vibronic levels. Spectral ranges of available QCL lasers are marked by grey shadow. In our experiment for detection of $\mathrm{NO}$ the line of $5.263 \mu \mathrm{m}$ was selected while the detection of $\mathrm{N}_{2} \mathrm{O}$ was performed at $4.530 \mu \mathrm{m}$. Such selection provides opportunity to avoid $\mathrm{H}_{2} \mathrm{O}$ interferences. These wavelengths correspond to emission characteristics of single mode sbcw3079 and sbcw1517, quantum cascade lasers (Alpes Lasers SA).

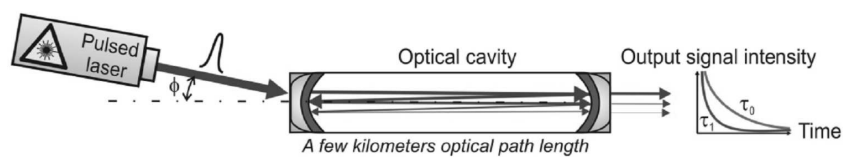

Fig. 4. Simplified scheme of the experimental system CEAS idea.

Simplified scheme of the single detection channel is presented in Fig. 4. Cavity enhanced absorption spectroscopy (CEAS) was applied [17,21]. It is a modification of the CRDS technique, which provides the opportunity to avoid a number of important problems that occur in common CRDS systems. Both the laser frequency and the cavity mode must be well matched to the absorption line. This is especially difficult when a precise tuning to a narrow spectral line is required. Mechanical instabilities of cavity length cause the instability of its modes which can induce the matching problems. CEAS provides an opportunity to overcome these difficulties. This method is based on the off-axis introduction of laser beam to the resonator. Inside the resonator the light is repeatedly reflected by the mirrors, however the light spots on the mirrors surfaces are spatially separated. Due to that, the free-spectral range of the off-axis cavity can be $n$ times smaller than in the case of the on-axis aligned, where $n$ denotes the number of the trips for which the ray returns to its entrance point and interferes with the input beam. Therefore, either the dense mode structure of low finesse occurs or the mode structure is not established at all. Avoiding the light interference allows to eliminate sharp resonances of the cavity. Consequently the problems connected with their coincidence with the laser mode and the 
sharp absorption line does not occur. In our experiment the lasers radiation tuned to absorption lines of $\mathrm{NO}_{x}$ was injected to each optical cavity under a very small angle in respect of its axis (Fig. 4). Quality of the resonator was investigated by measurement of the decay time of the radiation stored inside. The concentration of $\mathrm{NO}_{x}$ $\left(C_{\mathrm{NO} x}\right)$ was calculated using the formula [22]:

$$
C_{\mathrm{NO}_{x}}=\frac{1}{N_{0} c \sigma}\left(\frac{1}{\tau_{1}}-\frac{1}{\tau_{0}}\right)
$$

where $N_{0}$ denotes the Loschmidt number, $c$ - the light speed, $\sigma$ - cross-section for light absorption, $\tau_{1}$ - decay time of the radiation in the cavity with absorber, while $\tau_{0}$ - decay time in the cavity without absorber. In our system we observed the decay time $\tau_{0} \approx 3.8 \mu \mathrm{s}$.

\section{Results and discussion}

Setup of the sensor was shown in Fig. 5. It consists of two pulsed lasers with the control electronics, sample module, optical system and signal processing unit. Two optical cavities were used, for $\mathrm{NO}$ and $\mathrm{N}_{2} \mathrm{O}$, respectively. Each cavity was built with highly reflective spherical mirrors $(99.98 \%$, Los Gatos Research, Inc.). Their radius of curvature was $1 \mathrm{~m}$ while the distance between them was about $60 \mathrm{~cm}$. Investigated gases were delivered to the cavities from modular gas standards generator type 491 M (Kin-Tek), which also ensured the dust filtration and the moisture drying. Moreover, the generator assures automatic system clearance and the sensor calibrations with the use of inert gas.

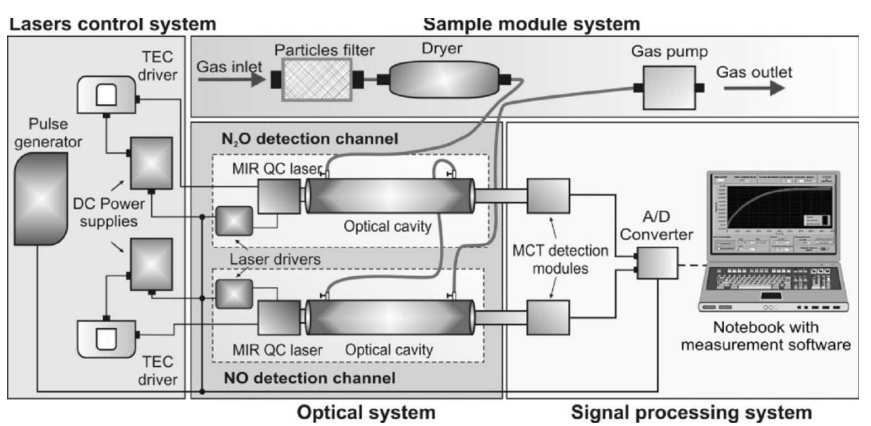

Fig. 5. CEAS sensor of nitrogen oxides block diagram.

The main task of the laser electronics is to stabilize parameters of QCL's. It was done with high quality power supplies (E3634A, Agilent). Laser wavelengths were precisely tuned to the selected absorption lines of $\mathrm{NO}_{x}$ using temperature as well as supply voltage and current control. The pulse shaping was done with DG645 generator (Stanford Research Systems, Inc.) connected to laser drivers (LDD400, Alpes Lasers).

Optical signals were registered with $\mathrm{HgCdTe}(\mathrm{MCT})$ photodetectors that use monolithic optical immersion technology. Thermoelectric cooling was applied. The photodetectors offer high detectivity (about
$10^{12} \mathrm{~cm} \sqrt{\mathrm{Hz}} / \mathrm{W}$ ) and high speed (up to $1 \mathrm{GHz}$ ). Transimpedance preamplifiers were applied in order to match output parameters of the photodetector to measuring circuit $[23-25]$. Signals from the preamplifiers were digitized using two-channel A/D converter. The data was transferred via USB interface to the portable computer equipped with special measurement software. The software automatically provides the gas concentrations.

For preliminary measurements an optical parametric oscillator (OPO from EKSPLA, model TG711/DSG) was used as a light source. While the energy of the light pulse from OPO $(8.9 \mu \mathrm{J}$ at $\lambda=4.50 \mu \mathrm{m})$ is much higher than the energy of QCL pulse, such procedure provides the opportunity to adjust the optical setup. Both $\tau_{0}$ and $\tau_{1}$ times (1) were determined for the cavity filled with pure $\mathrm{N}_{2}$ and $\mathrm{N}_{2} \mathrm{O}-\mathrm{N}_{2}$ (10 ppm) mixture, respectively. Comparison of these signals is presented in Fig. 6 .

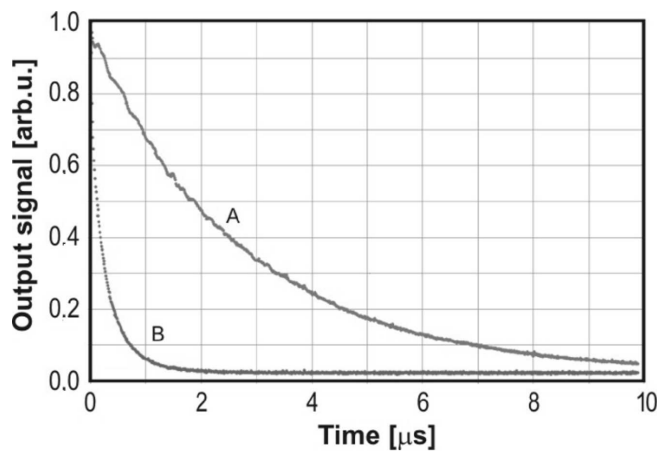

Fig. 6. Measurement with OPO: output signals from the cavity filled with reference gas $(A)$, and with $10 \mathrm{ppm}$ $\mathrm{N}_{2} \mathrm{O}(B)$.

The linewidth of parametric oscillator is about $0.001 \mu \mathrm{m}$ so when the peak of its line is tuned to $4.530 \mu \mathrm{m}$ the laser spectrum overlaps several absorption maxima of $\mathrm{N}_{2} \mathrm{O}$ spectrum (Fig. 3). In this spectral range mean value of the absorption cross-section reaches about $\sigma \approx 6 \times 10^{-19} \mathrm{~cm}^{2}$. Assuming that $\tau_{0} \approx 3.8 \mu$ s and the precision of decay time determination is $\Delta \tau / \tau_{0} \approx 2 \%$, using the formula [12]:

$$
N_{\mathrm{MIN}}=\frac{1}{c \sigma \tau_{0}} \frac{\Delta \tau}{\tau_{0}},
$$

one can evaluate that in such circumstances the registration of minimal concentration of $N_{\mathrm{MIN}} \approx 10 \mathrm{ppb}$ was possible.

The measurement was repeated with narrowband quantum cascade laser well tuned to $4.530 \mu \mathrm{m}$ absorption line. Peak cross-section at this wavelength reaches $8 \times 10^{-18} \mathrm{~cm}^{2}$, so essential decrease of output signals was observed (Fig. 7). Energy of QCL pulses were about two orders of magnitude lower, then the signals are much noisier. Plot $A$ in Fig. 7 corresponds to the signal registered when the cavity was filled with reference gas. Plot $B$ corresponds to the signal from the cavity filled with $10 \mathrm{ppm}$ of $\mathrm{N}_{2} \mathrm{O}$. Due to the absorption which was almost 
13 times larger than for measurement with OPO, the amplitude was quenched so strongly that neither the signal amplitude nor its decay time cannot be determined. Our gas filling system does not provide the opportunity to dilute the $\mathrm{N}_{2} \mathrm{O}$ concentration, however one can evaluate that good matching of laser line to the absorption spectrum provides the increasing of the sensitivity of detection system and provides the opportunity to a ppt level.

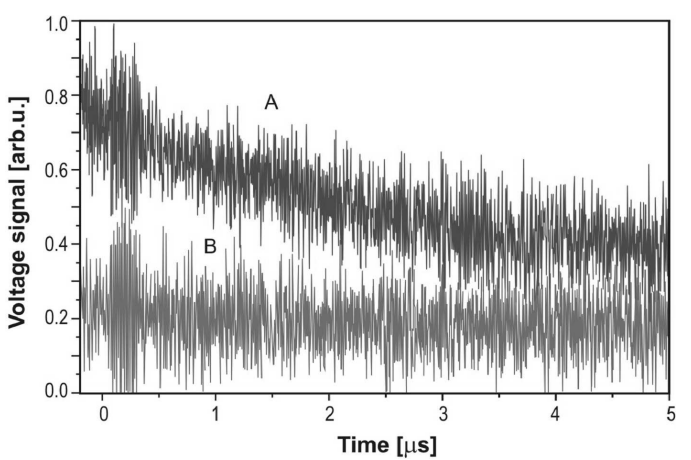

Fig. 7. Measurements with QCL: output signals for the cavity filled with reference gas $(A)$, and with $10 \mathrm{ppm}$ $\mathrm{N}_{2} \mathrm{O}(B)$

Detection of nitric oxide with quantum cascade laser is a matter of forthcoming experiment. While the absorption cross-section of $\mathrm{NO}$ is about ten times smaller the sensitivity of this sensor of about $1 \mathrm{ppb}$ is expected.

\section{Summary}

We presented construction of nitric oxide (NO) and nitrous oxide $\left(\mathrm{N}_{2} \mathrm{O}\right)$ sensors operating with quantum cascade lasers. CEAS technique was applied. During preliminary experiments with broadband parametric oscillator the sensitivity of $10 \mathrm{ppb}$ for $\mathrm{N}_{2} \mathrm{O}$ was achieved. The measurement with a specialized narrowband QCL working on a wavelength well matched to the peak of the absorption spectrum provide opportunity to increase this sensitivity to the level of $\mathrm{ppb}$ for $\mathrm{NO}$ and the level of $0.1 \mathrm{ppb}$ for $\mathrm{N}_{2} \mathrm{O}$.

\section{Acknowledgments}

The researches were supported by the Polish Ministry of Science and Higher Education, grant No. OR00002807.

\section{References}

[1] Hitran 2008 database, Ontar Corporation, www . ontar. com .

[2] J.H. Seinfeld, S.N. Pandis, Atmospheric chemistry and physics: from air pollution to climate change, sec. ed., Wiley, New Jersey 2006.

[3] B.A. Vandyshev, Special Purpose Technol. 1, 257 (1998).
[4] H. Schubert, A. Kuznetsov, Detection and disposal of improvised explosives, Springer, 2006.

[5] J. Yinon, Detection and disposal of improvised explosives, Wiley, Chichester 1999.

[6] T. Kondo, T. Mitsui, M. Kitagawa, Y. Nakae, Dig. Dis. Sci. 45, 2054 (2000).

[7] C. Wang, P. Sahay, Sensors 9, 8230 (2009).

[8] A.M. Winer, J.W. Peters, J.P. Smith, J.N. Pitts Jr, Environ. Sci. Technol. 8, 1118 (1974).

[9] W.A. McClenny, E.J. Williams, R.C. Cohen, J. Stutz, J. Air Waste Manag. Assoc. 52, 542 (2002).

[10] M.I. Mazurenka, B.I. Fawcett, J.M.F. Elks, D.E. Shallcross, A.J. Orr-Ewing, Chem. Phys. Lett. 367, 1 (2003).

[11] V.L. Kasyutich, C.S.E. Bale, C.E. Canosa-Mas, C. Pfrang, S. Vaughan, R.P. Wayne, Appl. Phys. B 76, 691 (2003).

[12] J. Wojtas, A. Czyzewski, T. Stacewicz, Z. Bielecki, Opt. Appl. 36, 461 (2006).

[13] J. Wojtas, Z. Bielecki, Opto-Electron. Rev. 16, 44 (2008).

[14] M. Nowakowski, J. Wojtas, Z. Bielecki, J. Mikołajczyk, Acta Phys. Pol. A 116, 363 (2009).

[15] K. Holc, Z. Bielecki, J. Wojtas, P. Perlin, J. Goss, A. Czyzewski, P. Magryta, T. Stacewicz, Opt. Appl. XL, 641 (2010).

[16] K.W. Busch, M.A. Busch, Cavity-Ringdown Spectroscopy, An Ultratrace-Absorption Measurement Technique, ACS Symposium Series, Washington DC 1999.

[17] G. Berden, R. Engeln, Cavity Ring-Down Spectroscopy: Techniques and Applications, WileyBlackwell, Chichester 2009.

[18] L. Menzel, A.A. Kosterev, R.F. Curl, F.K. Tittel, C. Gmachl, F. Capasso, D.L. Sivco, J.N. Baillargeon, A.L. Hutchinson, A.Y. Cho, W. Urban, Appl. Phys. B 72, 859 (2001).

[19] A. Grossel, V. Ze'ninari, L. Joly, B. Parvitte, G. Durry, D. Courtois, Infrared Phys. Tech. 51, 95 (2007).

[20] http://www.epa.gov/ttn/emc/ftir/ aedcdat $1 . \mathrm{html}$.

[21] R. Engeln, G. Berden, R. Peeters, G. Meijer, Rev. Sci. Instrum. 69, 3763 (1998).

[22] A. O' Keefe, D.A. Deacon, Rev. Sci. Instrum. $\mathbf{5 9}$ 2544 (1988).

[23] A. Piotrowski, P. Madejczyk, W. Gawron, K. Klos, M. Romanis, M. Grudzien, A. Rogalski, J. Piotrowski, Opto-Electron. Rev. 12, 453 (2004).

[24] A. Rogalski, Z. Bielecki, in: Handbook of optoelectronics, Eds. J. Dakin, R.G.W. Brown, Taylor \& Francis, New York 2006, p. 73.

[25] Z. Bielecki, W. Kolosowski, E. Sedek, M. Wnuk, J. Wojtas, in: Computational Methods and Experimental Measurements XIV, Eds. C.A. Brebbia, G.M. Carlomagno, WIT Press, Southampton 2009, p. 217. 